\title{
MODALIDAD E IRONÍA EN UN BOLERO DE LES LUTHIERS
}

\section{ONE LES LUTHIERS'BOLERO, MODE AND IRONY}

\author{
Miguel Ángel Caro Lopera* \\ Carlos Alberto Castrillón Ramírez ${ }^{* *}$
}

Caro L. Miguel A., Castrillón R. Carlos A. Sophia N 7 - 2011. ISSN: 194-8932 Págs. 160-169.

Recepción: Junio 29 de 2011

Aceptación: Agosto 10 de 2011

\section{RESUMEN}

Este artículo aborda la ironía de Les Luthiers en el frente de la modalidad deóntica, a través del análisis pragmático del bolero Perdónala, desde las teorías de Bally (1942, 1965), Schoentjes (2003) y Ducrot (1988). Nace de las investigaciones "Acercamientos a la retórica de la ironía en el discurso verbal de Les Luthiers" (Universidad Tecnológica de Pereira, 2009) y "Burlemas e infortunios en la ironía de Les Luthiers" (Universidad del Quindío, 2010), que han analizado cualitativamente la obra de Les Luthiers y que han definido su ironía como un infortunio pragmático con réplicas en todos los niveles del texto y el discurso.

PALABRAS CLAVE

Les Luthiers, ironía, análisis pragmático, modalidad, bolero.

\section{ABSTRACT}

This article discusses Les Luthiers irony towards deontic morality through the pragmatic analysis of the bolero "Perdónala" from the theoretical approaches of Bally (1942-1965) Schoentjes (2003) and Ducrot (1988). It arises from the following researches: "approaches to the rhetoric irony of verbal speech from Les Luthiers" (Universidad Tecnologica 2009), "Burlemas and misfortunes of Les Luthiers irony" (Universidad del Quindío 2010), both which have qualitatively analyzed the work of Les Luthiers and have defined irony as a pragmatic misfortune with replicas in all levels of discourse and text.

KEY WORDS

Les Luthiers, irony, pragmatic analysis, mode, bolero.

* Profesor del Departamento de Español y Literatura y miembro del Grupo de Investigación Dilema (Didáctica de la Lengua Materna y la Literatura), Universidad del Quindío (registro en Colciencias COL0048563, categoría C). maincaro@yahoo.com Colombia.

** Magister en Literatura de la Universidad Tecnológica de Pereira, Licenciado en Lingüística y Literatura de la Universidad del Quindío, Profesor del programa de Español y Literatura de la Universidad del Quindío y de la Maestría en Literatura de la Universidad Tecnológica de Pereira. Director de la línea de investigación en "Relecturas del Canon Literario" (Universidad del Quindío) e integrante del Grupo de Investigación en Didáctica de la Lengua Materna y la Literatura (Dilema) sonorilo@yahoo. com - Carrera 15 calle 12 Norte, Armenia, Quindío, Colombia. 


\section{INTRODUCCIÓN}

La inquietud por la retórica de la ironía en los discursos implicados en la obra de Les Luthiers ${ }^{1}$ se inscribe en el marco de una preocupación más amplia: el uso de la lengua en el contexto social, siguiendo las propuestas de Jankélévitch (1950), Haverkate (1985), Booth (1986), Berrendonner (1987), Ducrot (1988), González (1996), Schoentjes (2003) y Hutcheon (2003), entre otros. A modo de hipótesis, se parte de los soportes pragmáticos de la ironía, a los cuales se agregan los argumentativos y retóricos, recuperados de sus fuentes nutricias griegas y latinas por Perelman (1997) y por el mismo Watzlawick (1994), muchos pasos más allá de las tradicionales concepciones que han atomizado a la retórica antigua como simple colección de ornatos que habitan una elocutio.

Como hemos tratado de demostrar en Caro y Castrillón (en prensa) ${ }^{2}$, el recorrido se puede iniciar en el nivel fonológico y fonético, en el que la ironía de Les Luthiers aprovecha los pares mínimos fonológicos y todos los mecanismos relacionados con el Oulipo y los trabajos de Serra (2000), para despertar un primer diálogo de voces absurdas e irónicas con la complicidad del código sonoro de la lengua. En el nivel morfosintáctico, la ironía irrumpe de la mano de burlemas (derivaciones y síntesis fantásticas, infortunios morfológicos, simildesinencias y distorsiones semánticas), como fruto de los juegos con las reglas de asociación morfemática. En el campo de la pragmática, la ironía se explica por la violación de los roles de los participantes y de las normas de los juegos de lenguaje, al abrigo del principio del aptum. Allí, una variada mezcla de anacronismos, desaciertos, malas apelaciones, violaciones de condiciones preparatorias, isotopías de impotencia, generalizaciones inapropiadas, infortunios estilísticos, parodias, etc., al igual que actos viciados, huecos e insinceros, dan cuenta de un complejo entramado de rupturas. Al avanzar al plano de las

1 Para una historia completa de Les Luthiers y una descripción de su propuesta estética véanse Masana (2005) y Samper (2007).

2 Este artículo es un producto parcial de dos investigaciones: "Acercamientos a la retórica de la ironía en el discurso verbal de Les Luthiers" (Universidad Tecnológica de Pereira, 2009) y "Burlemas e infortunios en la ironía de Les Luthiers" (Universidad del Quindío, 2010). superestructuras textuales, el travestimiento de géneros emerge como uno de los procedimientos irónicos preferidos por Les Luthiers, gracias al cual se propician rupturas estilísticas, permutaciones abruptas entre tipologías, inversiones enunciativas y cambios de tonalidad.

Se concluye del recorrido que la retórica de la ironía de Les Luthiers funciona como un infortunio pragmático con réplicas en todos los niveles del texto y el discurso. Este infortunio, al que podríamos llamar -por su fuerza argumentativa- retórico, consigue la adhesión de la comunidad discursiva gracias a la carnavalización de los lenguajes y visiones de mundo que se comprometen. Esta conclusión dialoga bien con otras concepciones de la ironía, como la que la reconcilia con el quinismo (Sloterdijk, 2003), por lo cual es posible pensarla como la carnavalización extrema de los discursos, no para destruirlos, sino para redimensionarlos mediante la erosión de sus expresiones cristalizadas, estereotipos, ideologemas y paradojas internas.

En este artículo nos ocupamos del hábil aprovechamiento de la modalidad deóntica para la construcción de la ironía en una pieza de Les Luthiers. Del análisis se desprenden significativos matices argumentativos que relacionan este trabajo con los estudios actuales sobre la ironía en cuanto a su condición de juicio de valor, a su definición como rechazo por la alabanza y a su preferencia por argumentar desde las esencias.

\section{IRONÍA Y MODALIDAD}

La ironía se erige como una de las mejores piezas de artillería para derrumbar esencias, corroer paradigmas, carnavalizar teologías, enmohecer dogmas y fustigar ideologías. Booth (1986: 13) la define como algo que "abre vistas en las que reina el caos y, o bien libera mediante la destrucción de todo dogma o destruye por el procedimiento de hacer patente el ineludible cáncer de la negación que subyace en el fondo de toda afirmación". Schoentjes, por su parte, después de un periplo minucioso a través de sus distintos atavíos (desde el socrático hasta el posmoderno), humildemente se reconocerá incapaz de aportar una definición general y, más bien, apelará a la simbología que entraña el dibujo de la cubierta de su libro: un cisne negro y su imagen bastante distorsionada en el 
agua; de tal descripción concluirá que la ironía no hace algo distinto: "al enfrentar al lector a significados contradictorios, ella reclama una interpretación"; la propondrá, entonces, como "un juego de reflexión que, al poner las cosas a distancia, las pone en entredicho" (2003: 265). Sin embargo, a la hora de elegir una perspectiva teórica para avistar el fenómeno, apostamos por la de Ducrot (1988), en la que se articulan el dialogismo y el carnaval bajtinianos y se propone un interesante hermanazgo entre la polifonía y el humor. La pertinencia de una definición lingüística de la ironía y el humor es defendida por Ducrot (1988: 22) en el marco de la teoría de la significación:

Si bien es cierto que la ironía y el humor no pertenecen a la lengua y son simplemente utilizaciones de la lengua, también es cierto que en todas ellas se puede expresar el humor y la ironía: es un fenómeno universal. Me parece necesario entonces incluir en los conceptos generales utilizados para describir la significación lingüística, nociones que prevean la posibilidad de estas utilizaciones humorísticas o irónicas. Una descripción de la lengua que no previera esas posibilidades, sería una descripción bastante incompleta.

Recordemos que Ducrot califica de humorístico al enunciado que cumpla las tres condiciones siguientes:

a. Entre los puntos de vista representados en el enunciado, por lo menos, hay uno que obviamente es absurdo, insostenible (en sí mismo o en el contexto).

b. El punto de vista absurdo no es atribuido al locutor. c. En el enunciado no se expresa ningún punto de vista opuesto al punto de vista absurdo (no es rectificado por ningún enunciador) (1988: 20).

Dentro de los enunciados humorísticos, agregará más adelante Ducrot, se calificarán de irónicos "aquellos en que el punto de vista absurdo es atribuido a un personaje determinado, que se busca ridiculizar" (ibíd., 21). Así las cosas, el locutor elegirá un enunciador absurdo que se dirigirá a un enunciatario del mismo tenor. Paralelamente, el locutor construirá otro enunciador, el irónico, que se dirigirá a otro enunciatario, obviamente irónico, con un texto que navega en otro sentido ${ }^{3}$. El locutor, por el carácter ambiguo de la ironía, en ningún momento publicará su adhesión a este último enunciador, aunque colijamos a las claras su simpatía. Por su parte, el interlocutor percibirá el juego y dispondrá de un enunciatario absurdo que reciba lo producido por el enunciador de la misma índole y creará un enunciatario irónico con el que se identificará plenamente. Los problemas comunes de comprensión de la ironía surgen cuando el interlocutor se identifica ingenuamente con el enunciatario absurdo y no erige otro enunciatario capaz de adivinar la voz subrepticia del locutor. Así pues, en esta comunicación de doble vía, en esta construcción de enunciadores / enunciatarios alternos, consolida la ironía todo un circuito retórico gracias al cual se consigue la adhesión del interlocutor a la propuesta discursiva del locutor en el marco de una cultura, como lo muestra este esquema general:
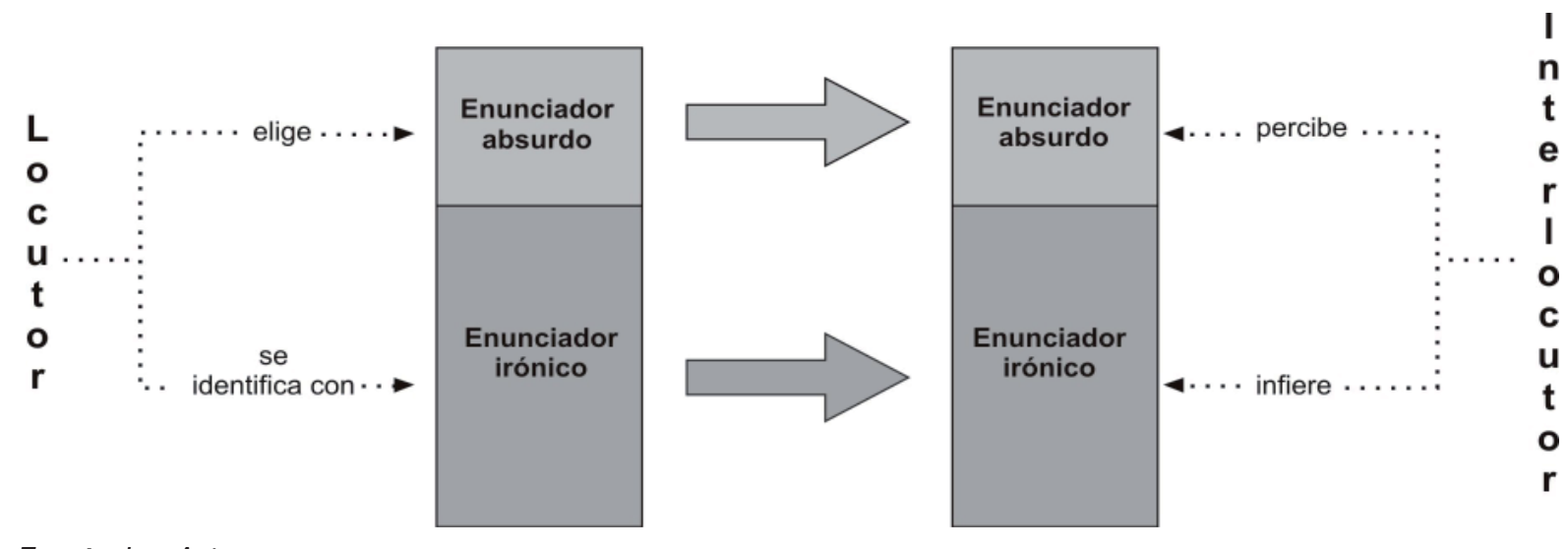

Fuente: Los Autores. 
Por otra parte, Bally (1942: 3) define la modalidad como "la forme linguistique d'un jugement intellectuel, d'un jugement affectif ou d'une volonté qu'un sujet pensant énonce à propos d'une perception ou d'une représentation de son esprit". De allí surge la clasificación inicial de los modalizadores aléticos, doxásticos y deónticos:

La phrase est la forme la plus simple possible de la communication d'une pensée. Penser, c'est réagir à une représentation en la constatant, en l'appréciant ou en la désirant. C'est donc juger qu'une chose est ou n'est pas, ou estimer qu'elle est désirable ou indésirable, ou enfin désirer qu'elle soit ou ne soit pas. On croit qu'il pleut ou on ne le croit pas, ou on en doute, en se réjouit qu'il pleuve ou on le regrette, on souhaite qu'il pleuve ou qu'il ne pleuve pas. Dans le premier cas, on énonce un jugement de fait, dans le second un jugement de valeur, dans le troisième une volition. La première opération relève de l'entendement, la deuxième du sentiment, la troisième de la volonté, qui a son aboutissement dans l'action, aboutissement qui est une des fonctions du langage tout en le dépassant. La pensée ne se ramène donc pas à la représentation pure et simple, en l'absence de toute participation active d'un sujet pensant (Bally, 1965: 35).

A la misma fuente apuntan Ducrot y Todorov (1972: 355) cuando aseveran que "la atribución de un predicado a un objeto puede presentarse como un hecho [modalidad alética], como una posibilidad [doxástica] o como una necesidad [deóntica]". En el mismo sentido, Álvarez (2005: 35) habla de modalizadores asertivos, apreciativos y deónticos. La importancia de la modalidad se resume bien en la famosa formulación de Bally para su definición de frase:

La modalité est l'âme de la phrase; de même que la pensée, elle est constituée essentiellement par l'opération active du sujet parlant. On ne peut donc pas attribuer la valeur de phrase à une énonciation tant qu'on n'y a pas découvert l'expression, quelle qu'elle soit, de la modalité (Bally, 1965: 36).

3 Resaltamos el indefinido "otro" y lo preferimos al calificativo "contrario", que las definiciones tradicionales de ironía han acuñado y que la emparentan con la antífrasis. Adherimos más bien a las posturas de Booth (1986), Fish (1992), González (1996), Torres (1999), Schoentjes (2003) y del mismo Ducrot, que evitan fijar a la ironía en la orilla opuesta de lo que se dice y más bien la dejan libre de navegar en cualquiera otro sentido.

\section{UN BOLERO DE LES LUTHIERS}

En medio de lo cotidiano y automático que puede ser el acto de comunicarnos, a veces se nos escapa la confluencia de voces, tonalidades, intenciones, textualidades, retóricas y visiones de mundo que se dan cita en un discurso. Una de las maneras más efectivas para aguzar la percepción ante la complejidad del lenguaje consiste en rastrear los diversos alcances de la ironía en el marco de un discurso verbal. La obra de Les Luthiers da cuenta de la bien planeada interpretación musical, de la ingeniosa invención de instrumentos o de la atractiva puesta en escena, tal como lo exalta la crítica del espectáculo, pero también ofrece una copiosa muestra de lo que una ironía aguda e irreverente logra cuando se escurre por entre los recovecos de la estructura de la lengua.

Los paradigmas, normas y mecanismos más sagrados de la lengua, así como los discursos que los congregan, desfilan por la obra de Les Luthiers llevando en parihuela las mejores figuras de un carnaval. En esta oportunidad, abordaremos algunos aspectos discursivos en el bolero "Perdónala" para rastrear la presencia de voces encontradas y de agudas ironías, como fruto del choque de modalizadores aléticos, doxásticos y deónticos. El bolero pertenece al concierto Les Luthiers unen canto con humor (1994) y fue incluido, sin modificaciones, en los recitales Bromato de Armonio (1998) y El Grosso Concerto (2001):

\section{Solista:}

No querría con Esther seguir viviendo, [1A] lo que hizo ya no puede perdonarse, [1B] que se vaya, no me agrada estar sufriendo, [1C] ciertas cosas no deben olvidarse. [1D]

Coro:

Perdónala, perdónala, [2A]

es dulce, te fue fiel, es una dama. [2B]

Perdónala, perdónala, [2C]

seguro que aún ella te ama. [2D]

Solista:

No querría con Esther seguir viviendo, [3A]

lo que pude perdonar lo he perdonado: [3B]

Esa tarde cuando ya se estaba yendo [3C]

confesó que ella nunca me había amado. [3D]

Coro:

Perdónala, no obstante, [4A]

regresa a aquellos besos como miel, [4B] 
Esther te fue leal, te fue constante [4C] y toda la vida te fue fiel. [4D]

Solista:

No querría con Esther seguir viviendo, [5A] nuestra vida fue amarga como hiel: [5B]

Esa tarde cuando ya se estaba yendo, [5C]

confesó que ella nunca me fue fiel... [5D] ¡Dale!

Coro:

Compréndela, ten calma, [6A]

fueron sólo veinte hombres hasta ayer [6B]

y piensa que en el fondo de su alma [6C]

esa muchacha es una dulce mujer. [6D]

Solista:

No querría con Esther seguir viviendo, [7A]

ya no puedo perdonar a esa muchacha. [7B]

Esa tarde cuando ya se estaba yendo, [7C]

me persiguió por la casa con un hacha. [7D]

Coro:

Tolérala es sólo una muchacha, [8A]

conviene que unos días no se vean. [8B]

Las mejores parejas se pelean [8C]

y casi todas se persiguen con un hacha [8D]

Solista:

No querría con Esther seguir viviendo, [9A]

mis amigos nunca fueron de su agrado. [9B]

Esa tarde cuando ya se estaba yendo, [9C]

opinó que eran todos unos vagos [9D]

Coro:

Olvídala, debes olvidarla, [10A]

de esa bruja, por fin, te liberaste. [10B]

Pero cuéntanos antes de olvidarla, [10C]

qué fue lo peor, lo que no le perdonaste. [10D]

Solista:

Lo último que hizo fue tremendo, $[11 \mathrm{~A}]$

eso sí que no puede perdonarse. [11B]

Esa tarde cuando ya se estaba yendo, [11C]

decidió quedarse. [11D]

\section{LA SERIE MODALIZADORA}

Muchos son los aspectos que aquí se pueden analizar, como la transformación de las representaciones, los procesos de significación, la enunciación, la discursividad y el análisis específico de la parodia del género, entre otros. Para nosotros, sin que la elección se deslinde de estos temas, despunta el duelo de voces entre el solista y el coro, en el terreno de la modalidad. La pieza se ajusta enteramente a los requisitos del bolero, no sólo por las características musicales (estructura vocal-instrumental y patrones rítmico, melódico y armónico), sino también por los topoi y la disposición de la letra (cuartetos con rima consonante $o$ asonante $A B A B$ ) y los otros aspectos mencionados. Desde la proxémica, en el escenario se advierte la estructura entre solista y coro, con turnos de intervención simétricos y alternados, lo que Calsamiglia y Tusón (2001: 35-36) consideran pares adyacentes, encadenados por "dos turnos normalmente consecutivos en los que el primero supone la aparición del segundo".

Este marco de distribución supone la presencia de voces distintas que se consolidarán desde las tesis y los modalizadores que las definen. Así pues, para el caso del solista, la posición es clara: su conclusión se consolida desde la anáfora al comienzo de cada una de las intervenciones: "no querría con Esther seguir viviendo". El coro, paladín de la unión conyugal, defenderá, al menos hasta su penúltima intervención, la opinión contraria, tesis que dará título al texto, "Perdónala", en la costumbre de tantos boleros bautizados desde la deprecación del locutor: "Bésame mucho", "Dime", "Niégalo", etc.

Observamos que en la primera intervención del solista $[1 \mathrm{~A}]$, el modalizador doxástico, "no querría", introduce el deseo del locutor de separarse de Esther; anhelo que viene complementado por otro modalizador del mismo orden, "que se vaya" [1C], expresado en subjuntivo, modo propio para la configuración del acto de habla de la petición de deseo. Refuerza esta voz la invocación de un topos que sentenciará la inconveniencia del perdón, a través de modalizadores deónticos taxativos como "lo que hizo ya no puede perdonarse"[1B] o "ciertas cosas no deben olvidarse" [1D]. Se observa cómo la actitud del hablante se deja ver tras el velo de las formas del verbo, como lo muestra López (2002: 26): "El mundo modal se [asienta] sobre el reparto de correspondencias entre las terminaciones verbales y los contenidos actitudinales".

Una vez configurada la tesis del solista, viene la mediación del coro, encabezada por el verbo perdónala en reduplicación [2A] y reiterado en anáfora en [2C]. La forma verbal, que toma la morfología propia del modo imperativo, se constituye en una de las presentaciones favoritas de la modalización deóntica, por cuanto elide formas del estilo de "tienes que perdonarla, es tu deber hacerlo"4. La interpelación se soporta 
en argumentos introducidos por un modalizador alético tácito en el verso [2B] y de uno doxástico explícito, "seguro que aún", en [2D]. Sin embargo, la situación se complica con la segunda intervención del solista, en la que insiste en su tesis [3A] y aporta lo que, en la retórica aristotélica, se considera como prueba extraartística: la declaración de Esther según la cual ella nunca lo había amado [3D]. Aquí el valor alético de "nunca" , añadido a la contundencia de la prueba, provoca en el coro la reacción que había advertido Aristóteles para este tipo de evidencias cuando resultan desfavorables al locutor: solaparlas, negarlas, rehuirlas... En este caso, el coro opta por una estrategia de atenuación, a través de la inserción del conector "no obstante" [4A], gracias a lo cual se establece un encuentro bi-vocal entre una conclusión que reconoce la razón al solista y otra más poderosa que lo exhorta al perdón, apoyada en los argumentos de la lealtad, constancia y fidelidad de Esther [4B], [4C] y [4D]. Para esto, el coro repite ex profeso el verbo ser al lado de cada adjetivo, con lo cual invoca modalizadores aléticos e incorpora argumentaciones desde la cantidad (Perelman, 1997), que vencerían 3 por 1 a la del solista:

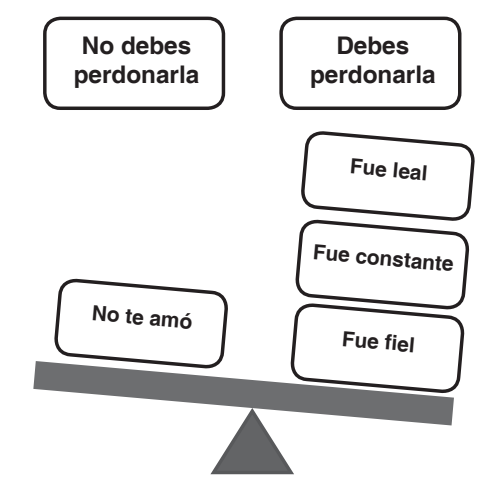

Fuente: Los Autores.

$4 \quad$ La similitud morfológica entre la modalización deóntica y la forma imperativa del verbo castellano permite a Les Luthiers armar juegos como este de "El acto en Banania", cuando el General Eutanasio Rodríguez dice: "Me duele que se piense que el nuestro es un gobierno autoritario. Que no se piense eso... ¡Es una orden!".

5 Las taxonomías en este campo resultan extremadamente difusas. Así lo reconocen Calsamiglia y Tusón (2001: 177) a la hora de abordar otras categorías, entre ellas la de usualidad, en la que se inscribiría este adverbio. Álvarez (2005: 35), sin embargo, lo incluye entre los asertivos.
Lamentablemente, el esfuerzo argumentativo del coro se verá expuesto a un nuevo ataque, ya que el solista rebatirá con una inesperada prueba extraartística la tan alabada fidelidad de Esther. La estructura se mantiene: los dos primeros versos con modalizador doxástico, [5A] y [5B], y los otros dos con la contundencia alética de la confesión de la aludida, [5C] y [5D]; razón por la cual, violando los cánones del bolero y más bien circunscrito a los de una conversación, el solista desafía a su interlocutor con un "idale!", que cumple funciones de conector pragmático y de modalizador deóntico (algo así como "tienes que responder esta nueva premisa si quieres que la perdone").

Ante tal reto, el coro no declina en la defensa de su protegida y opta por atenuar la gravedad del asunto y cambiar el curso de la argumentación. En cuanto a lo primero, elige un verbo de menor exigencia semántica para el burlado esposo, aunque empacado en igual tonalidad deóntica, "compréndela" [6A], y añade un modalizador alético que, al contacto con el dictum, crea un efecto irónico que desata las risas del público por la desproporcionada cantidad a la que se aplica: "fueron sólo veinte hombres hasta ayer" [6B]. Maltrecho el coro de este paso en falso, decide tender una columna de humo sobre la infidelidad consumada y desviar la atención del interlocutor hacia el último bastión que un topos podría defender en esta cultura: la bondad de la persona. Por eso, se deslizará otro modalizador deóntico en la intervención del coro: "y piensa que en el fondo de su alma esa muchacha es una dulce mujer" [6C] y [6D].

Hasta aquí, en el marco de lo permisible dentro del bolero, pueden llegar las concesiones del coro y las pruebas extraartísticas del solista. Para que la debacle sea total y este bolero deje de llamarse bolero y adopte la forma de uno de sus pastiches, el solista, en la misma estructura formal a la que ha fijado sus argumentaciones, hereda del coro el apelativo coloquial "muchacha" [7B] y con él consigue la más extrema de las rimas, la reina de las pruebas extraartísticas en contra de la bondad que han defendido sus amigos. En efecto, con el último verso, ya no estamos frente a una mujer incomprendida, sino a una psicópata que ha perseguido a su enamorado con un hacha [7D]. 
Sin embargo, el coro no se rinde. Tendrá que recurrir a un mayor arresto argumentativo para remar contracorriente ante una doxa que se hace casi irrebatible. Para ello, busca atenuar más la fuerza modalizadora de sus primeros versos. Así, del "perdónala" $[2 \mathrm{~A}]$ al "compréndela" $[6 \mathrm{~A}]$ y de este al "tolérala" [8A], las gradaciones alcanzan su generosidad más permisible. Esta estrategia no será suficiente, por lo que el mismo modalizador alético "sólo", que acompañó el exabrupto de "los veinte hombres" [6B], ahora camina solitario con el dictum "es una muchacha" [8A], desprovisto de cualquier adjetivo tan inmerecido como imposible y refugiado bajo el alar de lo deóntico. Ese mismo tono deóntico se prolonga de una manera muy sutil en [8B]: "conviene que unos días no se vean". Pero todo consejo resulta obsoleto si no viene sustentado por algún argumento, para lo cual el coro acude a una estrategia desesperada y falaz: apelar a la voz de la multitud, aquella que dicta la sentencia de que "[hasta] las mejores parejas se pelean" [8C]. Luego, con la entrada de tantas voces, el coro introduce una falacia ad populum, no sólo por la inoperancia del modalizador alético, "casi todas", sino también por la extravagancia de la mentira que inocula: "casi todas se persiguen con un hacha" [8D].
Justificado el fin de la persuasión con la inserción de cualquier medio argumentativo, cuando el coro ya cree ganada la batalla, el solista contraataca con una prueba extraartística que no sólo hiere la honra de sus consejeros, sino que también atenta contra uno de los topoi más defendidos en el bolero: el valor de la amistad. Por eso, con virulencia, el coro, al sentirse mancillado, olvida sus banderas y se pliega a la tesis que defendía el solista desde el principio, ya ni siquiera con modalizadores dúctiles, sino con todo el rigor de lo deóntico: "Olvídala, debes olvidarla, de esa bruja, por fin, te liberaste", [10A] y [10B]. En este punto, paralelo al hábil manejo de modalizadores, conviene resaltar la fina gradación que desde el "perdónala" hasta el "olvídala" va diseñando el coro a medida que las pruebas extraartísticas lo comprometen. Por último, disuelta la confrontación de posiciones, diluidos los antiguos roles de consejero - aconsejado y restituida la relación de complicidad, el solista termina con un modalizador doxástico en [11A] ("lo último que hizo fue tremendo") y uno deóntico en [11B] ("eso sí que no puede perdonarse"). Recojamos ese descenso vertiginoso desde el $100 \%$ de perdón en la primera estrofa hasta su ausencia total en la última, haciendo un cálculo aproximado de matices, como lo muestra el siguiente gráfico:

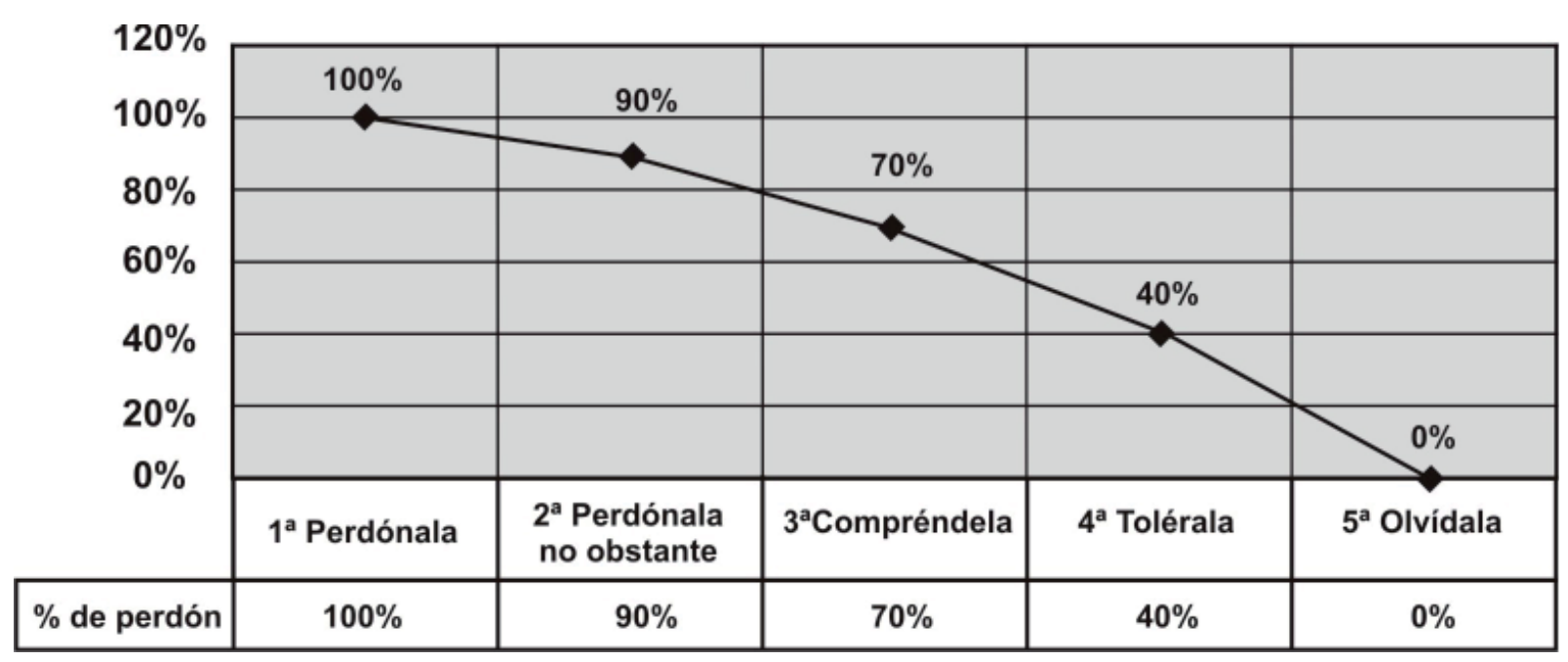

Fuente: Los Autores. 
De esta forma, apreciamos cómo los modalizadores han determinado el texto por completo al servir de soporte a la ironía. Un rápido conteo arroja las siguientes concurrencias y tendencias generales en las voces del solista y el coro:

\begin{tabular}{l|c|c|c}
\hline & Aléticos & Doxásticos & Deónticos \\
\hline Coro & 9 & 2 & 14 \\
\hline Solista & 6 & 10 & 4 \\
\hline Total & 15 & 12 & 18 \\
\hline
\end{tabular}

Fuente: Los Autores.

Si comparamos la presencia de modalizadores en uno y otro, obtenemos interesantes resultados. En lo doxástico hay una buena diferencia cuantitativa; sin embargo, cualitativamente hablando, la diferencia se acorta cuando advertimos que buena parte de las proposiciones que comparten esa modalización se repiten ("no querría con Esther seguir viviendo"). El contraste más evidente se aprecia en la modalización deóntica, que abunda en las intervenciones del coro. Los movimientos argumentativos de esta voz colectiva (gradación de la modalización, desequilibrio entre la conclusión y las premisas y solapamiento de pruebas extraartísticas), nos permiten suponer una mayor fuerza irónica en sus intervenciones, lo que confirma la conjetura sobre una mayor presencia de lo irónico en el plano deóntico. Igualmente, las intervenciones del coro son las que despiertan más risas del público; esto apoya la apuesta sobre la ironía como uno de los mecanismos discursivos que generan humor en la obra de Les Luthiers en calidad de efecto perlocutivo.

¿Qué encantos tiene la modalización deóntica para que la ironía se fije en ella? Una primera respuesta viene del estudio de Vázquez (2001: 13), donde revisa "desde una perspectiva lingüística el aspecto ético de la comunicación, pero aquel que se ha fijado en el sistema de la lengua". Seleccionar la modalidad deóntica no es una mera casualidad: "Es, quizás, uno de los fenómenos lingüísticos que con más claridad permite recopilar pruebas formales de la presencia de los interlocutores en el sistema de la lengua y de la significación de un tipo de relaciones sociales en la oración" (ibíd., 269). La presencia de interlocutores, la irrupción de voces en la palabra, la aparición del sujeto en la lengua, el carácter sociodiscursivo, hacen de la modalidad deóntica un caldo de cultivo especial para la ironía.

Por eso el énfasis del coro se cierne en lo exhortativo, en mover al solista a la acción, en obrar sobre su conducta, mediante formulaciones ("perdónala", "regresa", "compréndela", "ten calma", "piensa", "tolérala", "olvídala"), que invocan per se una mayor presencia de los hablantes, por cuanto se ciñen a una modalidad deóntica más subjetiva que objetiva (serían del corte de "yo te aconsejo que la perdones, que regreses, que la comprendas, que la olvides"). Ahora bien, en medio de este circuito comunicativo del yo que aconseja y del tú que valora hay una instancia interpretativa y evaluadora que nos interesa. Vázquez la describe así (ibíd., 267-268):

Una obligación o un permiso pierden su validez si no existe una valoración crítica entre los interlocutores para que el acto deóntico se establezca. Tanto la creación del acto deóntico como su valoración dependen de las formas lingüísticas que los hablantes escojan para significar dicho acto deóntico en "juego" (en el sentido de Wittgenstein), bajo determinadas condiciones. Dicho de otra forma, a este primer nivel de análisis de la sustancia (de la evaluación social) le he tratado de dar inteligibilidad con la posición del hablante y el oyente con respecto al acto deóntico, por medio de la estructura sintáctico-semántica de la oración (que ya es forma del contenido), bajo ciertas condiciones de satisfacción, aceptabilidad y validez del acto comunicativo.

Esas condiciones de satisfacción, aceptabilidad y validez cobran aquí alcances insospechados, ya que el consejo de "perdonar a Esther" a pesar del desamor, la infidelidad masiva y las agresiones extremas, o de "olvidar a Esther", por la premisa de que desdeñó a los amigos, sólo podría venir de un enunciador absurdo que se dirige a un enunciatario igualmente absurdo. Por tanto, dicha evaluación corresponderá a un enunciatario irónico invocado por el juego de la ironía, tal como lo recoge el siguiente esquema: 

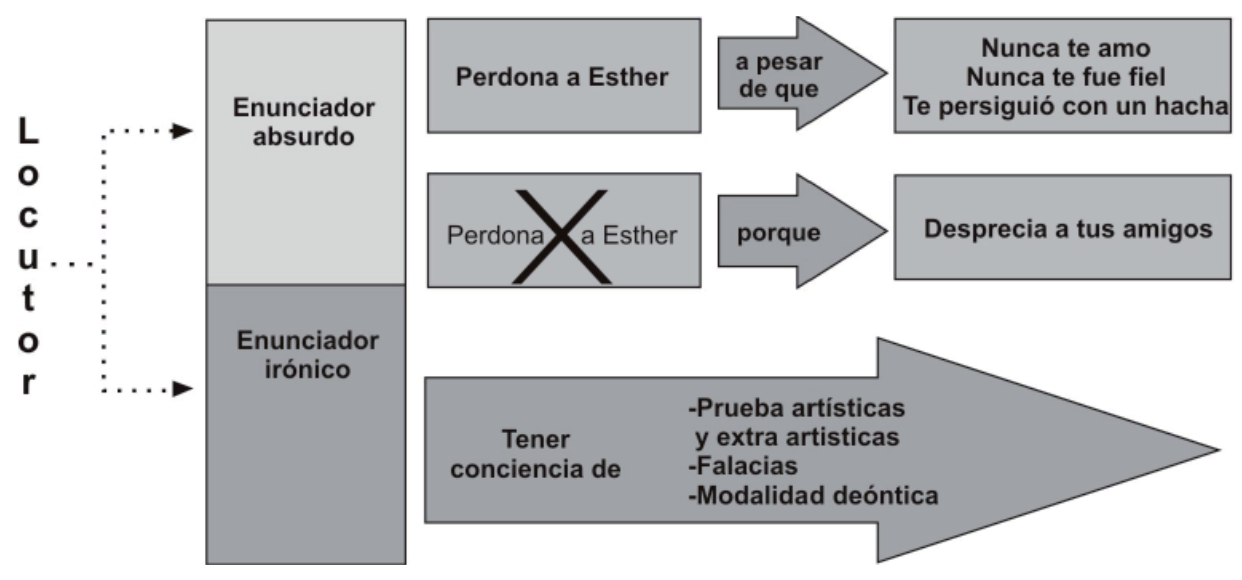

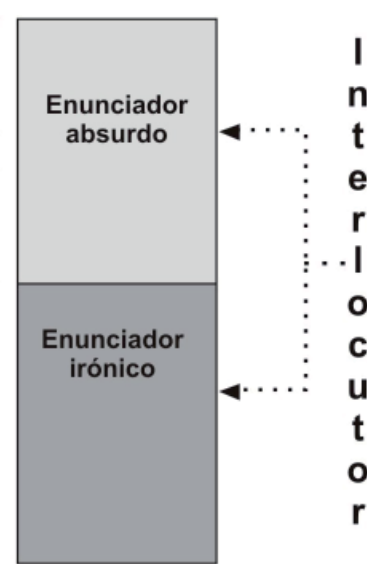

Fuente: Los Autores.

En este orden de ideas, razón tiene Vázquez cuando concluye su estudio afirmando que "la modalidad deóntica es la estrategia principal de los hablantes en la argumentación ética y moral, cuando buscan una nueva orientación de la acción social" (ibíd., 269). Dicha aseveración nos remite a la condición primera de los estudios sobre la ironía, ubicados, según Schoentjes (2003: 67), en el campo de la ética, gracias a las consideraciones de Anaxímenes sobre la eficacia de un tono neutro (el irónico) como instrumento retórico sin muchos predicamentos; para que haya ironía será preciso que un mismo objeto suscite dos opiniones contrarias. Por ello, basado en Quintiliano, Aristóteles y Cicerón, afirma Schoentjes (ibíd., 72) que "la ironía es siempre un juicio de valor". De premisas similares a esta, colige el autor que el irónico es, en esencia, un idealista, de ahí que "la dirección negativa que toma la evaluación en la ironía obliga a reconocer que el irónico se expresa siempre refiriéndose a un ideal moral" (ibíd., 76).

\section{CONCLUSIÓN}

Los disímiles esquemas argumentativos sustentan la ironía a través de la modalidad deóntica, tan cercana, entre otras cosas, al bolero. La voz irónica se camufla tan astutamente detrás del dictum y sus modalidades que no podríamos definir con certeza su posición o identificar con precisión alética el juicio de valor que espera Schoentjes. Tal vez el enunciador irónico no pretenda en este caso destruir el discurso que se ha tejido en torno a las relaciones de pareja; simplemente lo enriquece con nuevos sentidos. Les Luthiers no se burlan de sus personajes o de sus discursos (lo que nos trasladaría a los terrenos de lo cómico o lo meramente chistoso); más bien se ríen con ellos desde la explotación de las posibilidades absurdas que dejan traslucir las visiones de mundo en las que se inscriben. En el caso del bolero "Perdónala", la modalidad nos ha delineado un perfil discursivo de Esther que se acerca a la típica forma de argumentación por la esencia (Perelman, 1997), gracias a la cual la protagonista atrae para sí todas las características del tipo de mujer que representa.

Ese es precisamente otro de los atavíos favoritos de la ironía: una forma de argumentar por las esencias, cuando de nada sirve hacerlo por la cantidad, por la cualidad, por el orden o por lo existente, ya que, como lo escribe Schoentjes (2003: 81), "la ironía presenta dos sentidos contradictorios en un área de tensión; el desvío irónico nace del hecho de que la ironía expresa siempre lo uno y lo otro, el sí y el no". Podemos apreciar, así hayamos mirado el discurso a través de una de las tantas rendijas posibles, la presencia de esta forma de la ironía agazapada entre modalizadores, que, inocentes de su rol como catalizadores discursivos, nos han recreado a tal punto los mundos que representan, que ya no sólo nos reconcilian "con el arte de morder, sino también con el arte de reír" (Nietzsche, 1984: 227); en este caso no nos reiremos del bolero, del amor o sus demonios, sino con ellos, desde ellos y para ellos. 


\section{REFERENCIAS BIBLIOGRÁFICAS}

Álvarez, Teodoro. (2005). Didáctica del texto en la formación del profesorado. Madrid: Síntesis.

Bally, Charles (1942). "Syntaxe de la modalité explicite". Cahiers Ferdinand de Saussure, 2: 3-13.

Bally, Charles (1965). Linguistique générale et linguistique française. Berna: Francke.

Berrendonner, Alain (1987). Elementos de Pragmática Lingüística. Buenos Aires: Gedisa.

Booth, Wayne (1986). Retórica de la ironía. Madrid: Taurus.

Calsamiglia, Helena \& Tusón, Amparo (2001). Las cosas del decir: Manual de análisis del discurso. Barcelona: Ariel.

Caro, Miguel A. y Castrillón, Carlos A. (en prensa). Burlemas e Infortunios en la Ironía de Les Luthiers. Armenia: Universidad del Quindío.

Ducrot, Oswald \& Todorov, Tzvetan (1972). Diccionario Enciclopédico de las Ciencias del Lenguaje. Buenos Aires: Siglo XXI.

Ducrot, Oswald (1988). Polifonía y argumentación. Conferencias del seminario Teoría de la Argumentación y Análisis del Discurso. Cali: Universidad del Valle.

Fish, S. (1992). Práctica sin teoría. Barcelona: Destino.

González, Rosario (1996). "Texto y contexto: La ironía como fenómeno del discurso". Revista Española de Lingüística, (26): $57-69$

Haverkate, Henk (1985). "La ironía verbal: análisis pragmalingüístico". Revista Española de Lingüística, (15): 343-391.

Hutcheon, Linda (2003). "Política de la ironía". En Schoentjes, Pierre. La poética de la ironía. Madrid: Cátedra. 241-250.

Jankélévitch, Vladimir (1950). L'Ironie ou la bonne conscience. Paris: Presses Universitaires de France.

López, Juan (2002). El modo: la categoría gramatical y la cuestión modal. Santiago de Compostela: Universidade, Servicio de Publicaciones e Intercambio Científico.

Masana, Sebastián (2005). Gerardo Masana y la fundación de Les Luthiers. Madrid: Belacqua.

Nietzsche, Friedrich (1984). Humano, demasiado humano. Madrid: Edaf.

Perelman, Chaïm (1997). El imperio retórico. Retórica y Argumentación. Santafé de Bogotá: Norma.

Samper, Daniel (2007). Les Luthiers, de la L a la S. Barcelona: Ediciones B.

Schoentjes, Pierre (2003). La poética de la ironía. Madrid: Cátedra.
Serra, Màrius (2000). Verbalia, Juegos de palabras y esfuerzos del ingenio literario. Barcelona: Península.

Sloterdijk, Peter (2003). Crítica de la razón cínica. Madrid: Siruela.

Torres, María A. (1999). Aproximación pragmática a la ironía verbal. Cádiz: Universidad de Cádiz.

Vázquez, María E. (2001). La arquitectura lingüística del compromiso: Las oraciones de debe ser. México: El Colegio de México.

Watzlawick, Paul (1994). El lenguaje del cambio. Barcelona: Herder. 